\title{
Climatic Characteristics and Determination Method for Freezing Rain in China
}

\author{
Yue Zhou, ${ }^{1,2}$ Yanyu Yue, ${ }^{3}$ Zhengxu Gao, $^{2}$ and Yuehua Zhou ${ }^{2}$ \\ ${ }^{1}$ Hubei Key Laboratory for Heavy Rain Monitoring and Warning Research, Institute of Heavy Rain, \\ China Meteorological Administration, Wuhan 430205, China \\ ${ }^{2}$ Wuhan Regional Climate Center, Wuhan 430074, China \\ ${ }^{3}$ Wuhan Central Meteorological Observatory, Wuhan 430074, China
}

Correspondence should be addressed to Yue Zhou; zhouyue8510@163.com

Received 2 May 2017; Accepted 27 August 2017; Published 8 October 2017

Academic Editor: Anthony R. Lupo

Copyright (C) 2017 Yue Zhou et al. This is an open access article distributed under the Creative Commons Attribution License, which permits unrestricted use, distribution, and reproduction in any medium, provided the original work is properly cited.

The climatic characteristics and temperature profiles of freezing rain in China are analyzed based on the observational data at 650 stations in China from 2000 to 2015. The freezing rain of China is generally in stripe-shape spatial distribution. The stations with freezing rain over 100 station-hours are mainly concentrated at the southeast areas of Southwest China and high-elevation mountainous areas of Eastern China. There are mainly two types of freezing rain temperature profiles, including single-warmlayer profile and double-warm-layer profile. The freezing rain profiles of mountainous area and urban area in Southwest China are similar to each other, and the freezing rain in Central and East China shares the similar single-warm-layer profile. The profiles in South China show the characteristics of freezing rain's profile in both Southwest China and Central/East China as the position of stations. PA of freezing rain's profiles is negatively correlated with NA, with correlation coefficients ranging from -0.36 to -0.70 . The configuration of weak cold/warm layer (both smaller than $150^{\circ} \mathrm{C} \cdot \mathrm{hPa}$ ) is one of major reasons causing frequent freezing rain at mountainous areas of Southwest China. The more obvious the change of NA with the variations of PA is, the more the freezing rain is likely to occur.

\section{Introduction}

Freezing rain is basically a precipitation process, in which the liquid raindrops are in supercooled state before reaching the ground and immediately turns into the frozen raindrops when they contact with objects less than $0^{\circ} \mathrm{C}$. Freezing rain is more likely to occur in early winter or the turning period between winter and spring when the confluence of coldwarm air mass is frequent. When freezing rain drops contact with objects, it will result in a denser $\left(0.8-0.9 \mathrm{~g} \mathrm{~cm}^{-3}\right)$, harder, transparent ice layer on the surface of object. Freezing rain is a severe disastrous weather, with the relatively lower frequency of occurrence. Freezing rain in mountainous area can seriously affect the normal operation of various field facilities, such as transmission line towers, telecommunication towers, and wind driven generators, and even cause the damage and collapse of these facilities [1-3]. Freezing rain is the natural hazard causing the accidents of $66 \mathrm{kV}$ and the above voltage-level transmission lines, whose number is second to that of lightning hazard. From 2005 to 2012, the annual number of overhead line accidents caused by freezing rain was 725 . Particularly in 2008 , the number of accidents, such as collapsed tower and line breaking, caused by freezing rain was as high as 3169 , which caused immeasurable socioeconomic loss [4]. The freezing rain which happened in urban area will lead to formation of icy layer on the surface of sidewalk, roadway, and viaduct, thus severely affecting people's daily traveling, production, and living. In November 22, 2016, freezing rain happened in the nighttime of Wuhan and lasted for a few hours, which led to more than a hundred of road accidents, closure of multiple high ways, ferry suspension, and traffic control for all cross-river bridges and many viaducts in the daytime of the next day, greatly affecting people's working-trip. 
As freezing rain lasts for relatively short time, it is impossible to make statistical analysis to the number of freezing rain days. Therefore, former researches are mainly concentrated on the distributions of days of glaze and rime. Glaze and rime are widely distributed in China. Except for eastern Sichuan, most area of Yunnan, southern Guangdong, southern Guangxi, and Hainan island where ice-freezing has nearly never occurred before, other areas of China all experienced glaze and rime weather [5]. It is worth noting that glaze is almost in the southern part of China, while rime is mainly in the northern part of China. Mountainous area has higher occurrence frequency of glaze and rime than plain area [6]. With the increase of altitude, the freezing weather is more and more serious [7]. The days of ice-freezing, glaze, and rime in China are decreasing, while the intensities of these weathers are increasing, with thicker icing [8]. Glaze mainly occurred in Guizhou, Hunan, Jiangxi, Yunnan area, and so on and is usually caused by the occurrence of freezing rain, which is of higher catastrophability and more difficult to be formed than the rime. However, there are few statistical researches on freezing rain which lasts for short time but leads to serious damage.

There are normally two formation mechanisms of freezing rain: melting process and supercooled warm rain process. Melting process can be described as that when there is a warm layer greater than $0^{\circ} \mathrm{C}$ lying on cold air, snow or ice crystal falls through the warm layer and melts into liquid drop. Subsequently, the liquid drops fall through near-surface cold layer, turn into the supercooled state, and immediately freeze on the contacting-object surface. The melting process mainly occurred on the side of warm front [9]. The existence of warm layer greater than $0^{\circ} \mathrm{C}$ and thermal inversion layer is the main features of melting process [10]. Supercooled warm rain process refers to that when there is no warm layer greater than $0^{\circ} \mathrm{C}$, the size of supercooled cloud droplets (diameter larger than $40 \mu \mathrm{m}$ ) increases by collision-coalescence, which is the main mechanism for the formation of freezing drizzle. Supercooled warm rain process mainly occurs in the upper air or mountainous area, which is one of major reasons for aircraft icing [11, 12]. Huffman and Norman [13] as well as Bocchieri [14] conducted statistical analysis of the freezing rain in America and pointed out that more than $60 \%$ of freezing rains are formed by melting process. Moreover, the "melting process" commonly existed in the freezing rain process observed by meteorological station which mainly located in plain areas [15]; therefore, the stratification characteristic codetermined by warm and cold layer is the main factor affecting the precipitation type. The change of $0.5^{\circ} \mathrm{C}$ may cause the conversion of precipitation form [16, 17], showing that just a little change of the temperature would lead to the transformation of precipitation form.

In scientific research, the judgment of precipitation type is normally realized by physical models consisting of various microphysical processes. However, such method is mainly designed for case study as it requires large calculation resource and spends more time and is also affected by local environment easily. In contrast, the method of judging precipitation type using key features of atmospheric stratification profile as main factors is obtained by summarizing historical data of freezing rain profiles in various areas, possessing favorable local applicability and can be well applied for multifield climate operation services. Regarding the stratification characteristics of different precipitation types, scholars in North America with high frequency of freezing rain conducted many researches. Derouin [18] determined precipitation types based on the freezing layer height. However, this method did not consider the vertical stratification distribution. Cantin and Bachand [19] used the mean temperature of two layers at $1000-850 \mathrm{hPa}$ and $850-700 \mathrm{hPa}$ as predictor and considered vertical movement intensity and synoptic situation, while such method is mainly applicable for eastern part of Canada and with lower practicability for other areas especially mountainous areas. Ramer [20] proposed taking the temperatures, relative humidity, and wet bulb temperatures of various isobaric surfaces as index to determine the precipitation types. Houston and Changnon [21] pointed out that the profiles of dry-bulb temperature and dew-point temperature are the key factors for judging precipitation type. However, these methods have poor feasibility owing to low practicability studies at different areas and do not clearly illustrate the physical meaning of disparate impact of different temperature stratifications on precipitation particles. Therefore, we applied the research method of Bourgouin [22], which believed that the mean temperature of various layers and precipitation particle's residence time in various layers are the major factors of precipitation type, and the product term of the two indexes can be used as predictor to judge precipitation type.

Previous researches mainly focus on the distributions of glaze, rime, and climatic characteristics of them in different provinces of China [23-27], while the statistical analysis on freezing rain in the whole China is relatively fewer [5], and researches on distribution laws, climatic features, and quantitative judgment of freezing rain are much less. Regarding this problem, this paper presented a comprehensive and detailed analysis on the spatial distributions, climatic statistical features, and quantitative judgment of freezing rain in various areas of China, in the hope of providing certain help for meteorological and electric power departments in facing freezing rain disaster and providing theoretical basis for improving objective-forecasting ability to freezing rain.

\section{Data and Methods}

2.1. Data. The data was subjected to the quality control and arrival-rate selection in this paper, including the sounding data collected from 112 sounding stations of China at 08:00 and 20:00 BST as well as the ground meteorological elements data (air pressure, temperature, wind direction, wind speed, and the weather phenomenon) collected from 650 stations of China at 02:00, 05:00, 08:00, 11:00, 14:00, 17:00, and 20:00 BST from 2000 to 2015 . The weather phenomenon codes of $24,56,57,66$, or 67 represent that the freezing rain occurs at the moment in this station [28], and it will be denoted as one station-hour freezing rain in the following analysis. The application of station-hour could well identify the short-period freezing rain process, accurately position the time point when freezing rain is likely to occur, and 


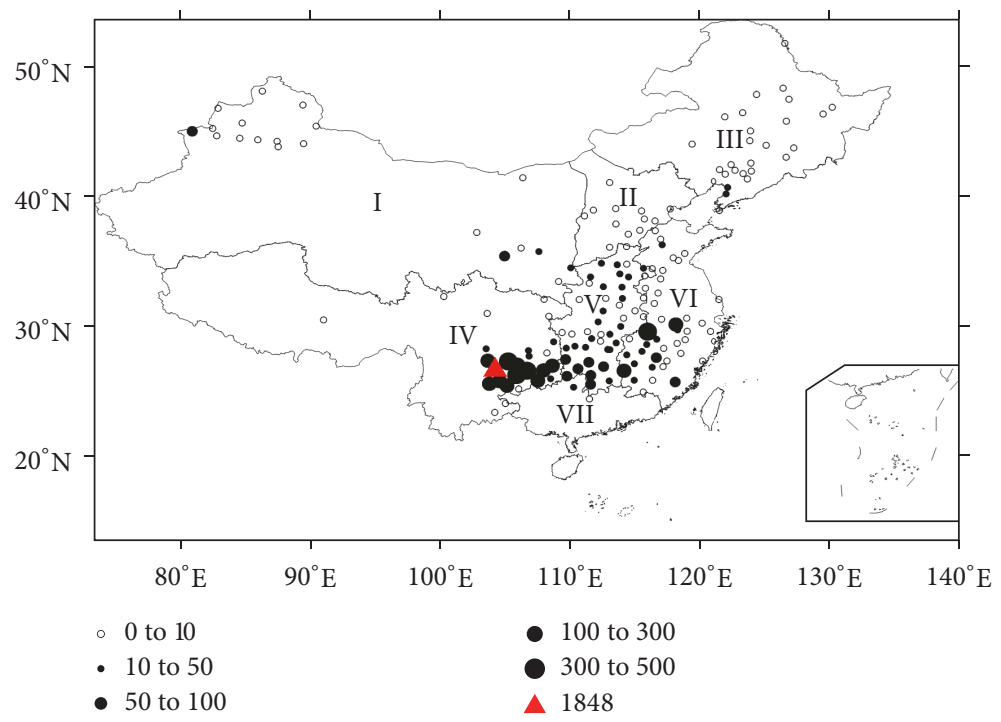

Figure 1: Distribution of freezing rains in China from 2000 to 2015 (unit: station-hour): (I) Northwest China; (II) North China; (III) Northeast China; (IV) Southwest China; (V) Central China; (VI) East China; (VII) South China.

carry on better study on the ground meteorological factors and characteristics of stratification profiles at corresponding moment.

2.2. Method. As stated previously, the vertical temperature profile is the main determinant of precipitation type. When precipitation particles go through the different temperature stratifications, the temperature and phase state of precipitation particle are mainly affected by the temperatures of warm and cold layers near the surface, as well as the residence time in corresponding stratification. Moreover, the residence time of particle in stratification can be indirectly reflected by the thickness of stratification, which is represented by the difference of air pressure observed at two elevations. This is due to that when precipitation particle goes through warm layer, it will absorb heat to increase temperature or to be even melted; while it goes through cold layer, it will emit heat to reduce temperature or to be even frozen. The amount of absorbed/emitted heat is determined by the intensity of warm/cold layer. The intensity of warm layer refers to the area which circled the profile with temperature higher than $0^{\circ} \mathrm{C}$ and $0^{\circ} \mathrm{C}$ isotherm, that is, positive energy area (PA). Similarly, the cold layer intensity refers to the area circled by the profile with temperature lower than $0^{\circ} \mathrm{C}$ and $0^{\circ} \mathrm{C}$ isotherm, that is, negative energy area (NA). By analyzing the distributions of PA and NA and the relationships between these two values at different regions of China during freezing rain events, a quantitative judgment method to freezing rain can be proposed.

\section{Results}

\subsection{Temporal-Spatial Distribution of Freezing Rain}

3.1.1. Spatial Distribution. China has broad territory with various landforms and climatic features among different areas.
Freezing rain is affected by these factors; China was divided into 7 regions including Northwest China, North China, Northeast China, Southwest China, Central China, East China, and South China according to common geographical partition method in our paper. Figure 1 shows the spatial distribution of freezing rain in China from 2000 to 2015. It can be seen that all of 7 regions have the occurrence of freezing rain, wherein the freezing rain is more frequent in Southwest China, Central China, and East China. Freezing rain occasionally happens in Northwest China, North China, and Northeast China and only appears in Guilin $\left(25^{\circ} 19^{\prime} \mathrm{N}\right.$, $\left.110^{\circ} 18^{\prime} \mathrm{E}\right)$ and Hexian $\left(24^{\circ} 25^{\prime} \mathrm{N}, 111^{\circ} 31^{\prime} \mathrm{E}\right)$ which locate in the northern boundary of South China. The distribution of freezing rain shows a "strip-shaped" feature in China, which is consistent with the spatial distribution of temperature. The low temperature of three regions in the north of China makes freezing rain unlikely to occur, also the excessive high temperature is the reason why freezing rain would not occur in south part of South China. The three central regions of more freezing rain events are due to the exchange of warm and cold air masses, especially for the areas around $26^{\circ} \mathrm{N}$ latitude. There are 175 stations of freezing rain throughout China, accounting for $26.9 \%$ of total observation stations. Among them, there are 113 stations with 0 10 station-hours, which mainly distribute at northwest areas of Northwest China, North China, the south areas of Northeast China, Central China, and central and north areas of Eastern China; there are 37 stations with 10 50 station-hours, which mainly distribute at north and south areas of Central China and the areas of Southwest China and Eastern China which are close to Central China; there are 10 stations with 50 100 station-hours, which mainly distribute at south areas and nearby areas of Central China; there are 10 stations with 100 300 station-hours, which mainly distribute at southeast areas of Southwest China and high-elevation mountainous areas (Mount Huang $\left(30^{\circ} 8^{\prime} \mathrm{N}, 118^{\circ} 9^{\prime} \mathrm{E}\right)$ and Jinggang Mountains 


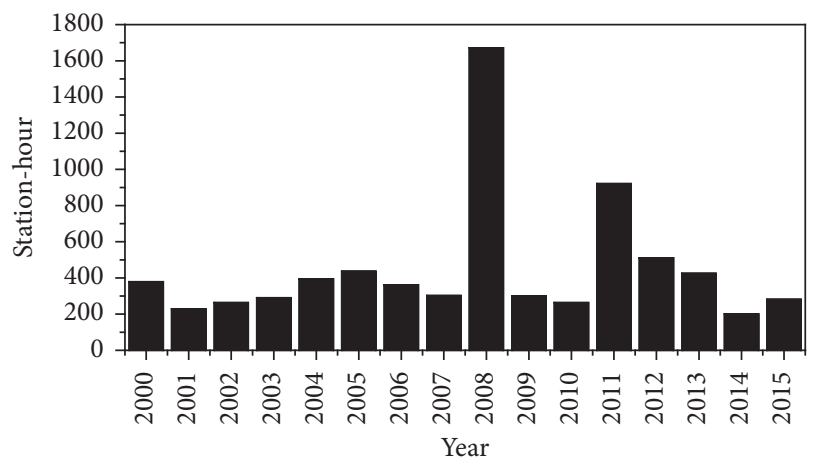

(a)

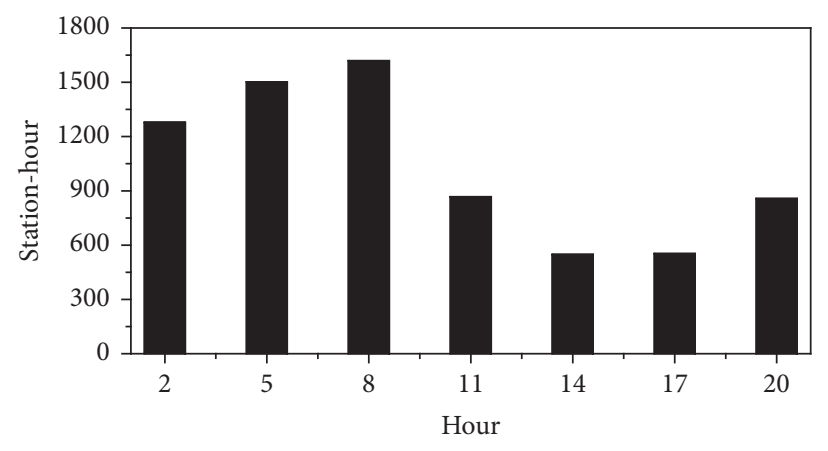

(b)

FIgURE 2: Temporal variation of freezing rain in China from 2000 to 2015. (a) Year and (b) daily.

$\left.\left(26^{\circ} 35^{\prime} \mathrm{N}, 114^{\circ} 10^{\prime} \mathrm{E}\right)\right)$ of Eastern China; there are 4 stations with 300 500 station-hours, which are mainly distributed at southeast areas of Southwest China and high-elevation mountainous areas (Mount $\mathrm{Lu}\left(29^{\circ} 35^{\prime} \mathrm{N}, 115^{\circ} 59^{\prime} \mathrm{E}\right)$ ) of Eastern China. Locating at altitude as high as $2236 \mathrm{~m}$, Weining $\left(26^{\circ} 52^{\prime} \mathrm{N}, 104^{\circ} 17^{\prime} \mathrm{E}\right)$ of Guizhou province observes the longest station-hours of freezing rain (1848 station-hours), which is significantly longer than that of the nearby stations.

It is worth noting that stations with over 100 stationhours are mainly concentrated at middle part and most southern areas of Guizhou province $\left(24^{\circ} 37^{\prime} \mathrm{N}-29^{\circ} 13^{\prime} \mathrm{N}\right.$, $\left.103^{\circ} 36^{\prime} \mathrm{E}-109^{\circ} 35^{\prime} \mathrm{E}\right)$, southeast areas of Yunnan $\left(21^{\circ} 8^{\prime} \mathrm{N}-\right.$ $\left.29^{\circ} 15^{\prime} \mathrm{N}, 97^{\circ} 31^{\prime} \mathrm{E}-106^{\circ} 11^{\prime} \mathrm{E}\right)$ neighboring Guizhou, and highelevation mountainous areas such as Mount Huang, Mount Lu, and Jinggang Mountains. The spatial distribution of freezing rain shows that the areas located at $106^{\circ} \mathrm{E}$ longitude and $26^{\circ} \mathrm{N}$ latitude are high incidence area. The climatic condition and high elevation make Guizhou the most affected province by freezing rain.

3.1.2. Temporal Distribution. Freezing rain is a meteorological disaster of less occurrence frequency with large impact. Figure 2 shows the variation of freezing rain in China from 2000 to 2015 . The annual variation of freezing rain's station-hour is featured by small fluctuation with sudden rises (Figure 2(a)). For each year, freezing rain of around 300 station-hours is the normal situation of its interannual variation. In 2008, 2011, and 2012, the frequencies of freezing rain are over 500 station-hours, with values of 1671,921 , and 510 station-hours, respectively. With the enhancement of climate change background, the extreme weather and hazard events increased [8], and the variation extent of freezing rain during 2008-2015 is significantly stronger than that during 2000-2007.

By further analysis to the daily variation of freezing rain (Figure 2(b)), the occurrence frequency of freezing rain is the lowest at 14:00 when the air temperature is the highest in one day, with only 548 station-hours. As time goes on, the occurrence frequency of freezing rain is gradually increased; especially after the midnight, the low air temperature and the thermal inversion layer which are likely to occur in winter lead to a significantly increased occurrence frequency of freezing rain. The station-hours of freezing rain are 1278 and 1502 at 02:00 and 05:00, respectively, and reach the highest value of 1619 station-hours at 8:00. The stationhours of freezing rain during 20:00 08:00 are 2.7 times of those during 11:00 17:00. The daily variation of station-hours of freezing rain exhibited the distribution law of "more in nighttime and less in daytime," similar to the statistical results of freezing rain in North America [29], which hinder the relevant administrations from taking measures to overcome its secondary disasters severely, thus greatly affecting people's production and living.

3.2. Meteorological Conditions of Freezing Rain. Figure 3 shows the statistic characteristics of meteorological elements in different regions during the freezing rain events. When freezing rain happens, the air temperature at $2 \mathrm{~m}$ height is within the range of $-8 \sim 2^{\circ} \mathrm{C}$, and the mean temperature is around $-1^{\circ} \mathrm{C}$, which is relatively lower at Northwest China $\left(-2.5^{\circ} \mathrm{C}\right)$, but relatively higher at South China (near $\left.0^{\circ} \mathrm{C}\right)$. At Northwest China and Northeast China, the temperature distribution range is the largest, reaching $9^{\circ} \mathrm{C}$, while the variation range of temperature at other areas is around $3.5^{\circ} \mathrm{C}$. It is worth noting that, at Southwest China, Central China, and Eastern China of larger station-hour of freezing rain, the temperatures are all lower than $1^{\circ} \mathrm{C}$, and the air temperature is larger than $-3^{\circ} \mathrm{C}$ accounting for nearly $90 \%$, which is also a temperature range in which the freezing rain is likely to occur in China.

With regard to relative humidity, the range when freezing rain happens is significantly larger than that in the rime processes. Freezing rain can happen without saturation of atmosphere or the occurrence of fog, while the configuration of cold/warm layer at lower and middle level is more important. At areas of South China, the relative humidity is relatively small of the mean value lower than $80 \%$ when freezing rain happens. However, nearly $75 \%$ of freezing rain events occur when the relative humidity is above $85 \%$ at other areas. This is because the freezing rain is mainly concentrated at mountainous areas where the simultaneous appearance of fog and rain in supercooled state is the mainly reason causing freezing disaster [30,31], and the occurrence of supercooled fog accounts for the high relative humidity. The 


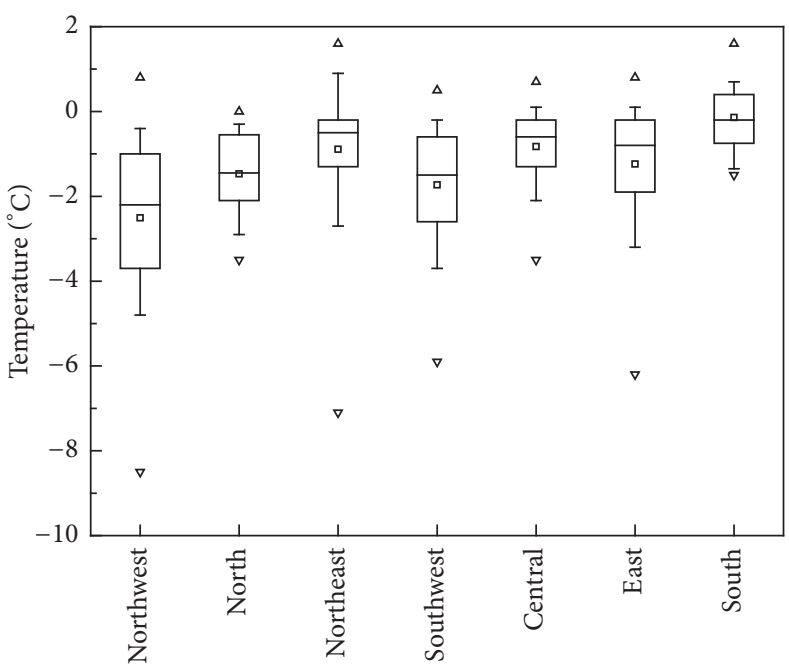

(a)

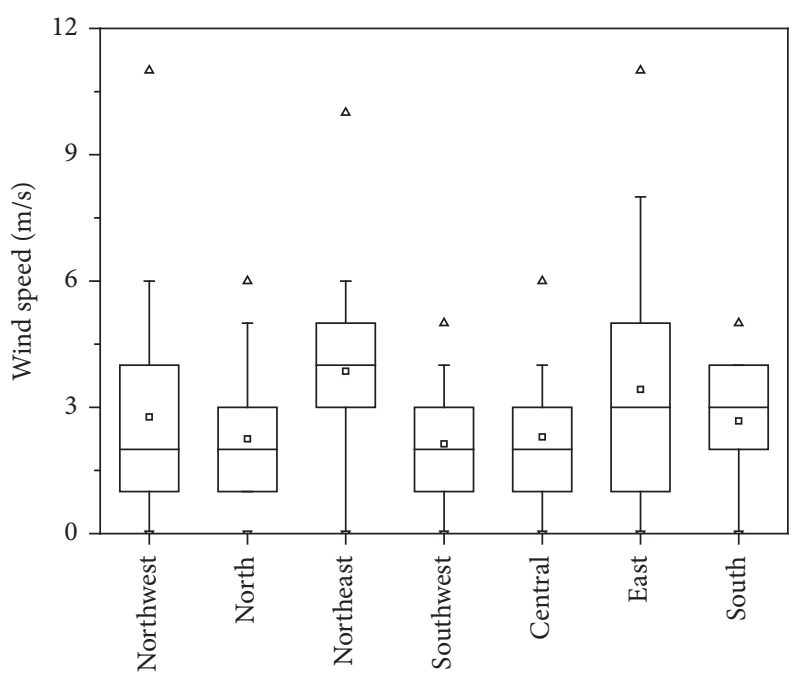

(c)

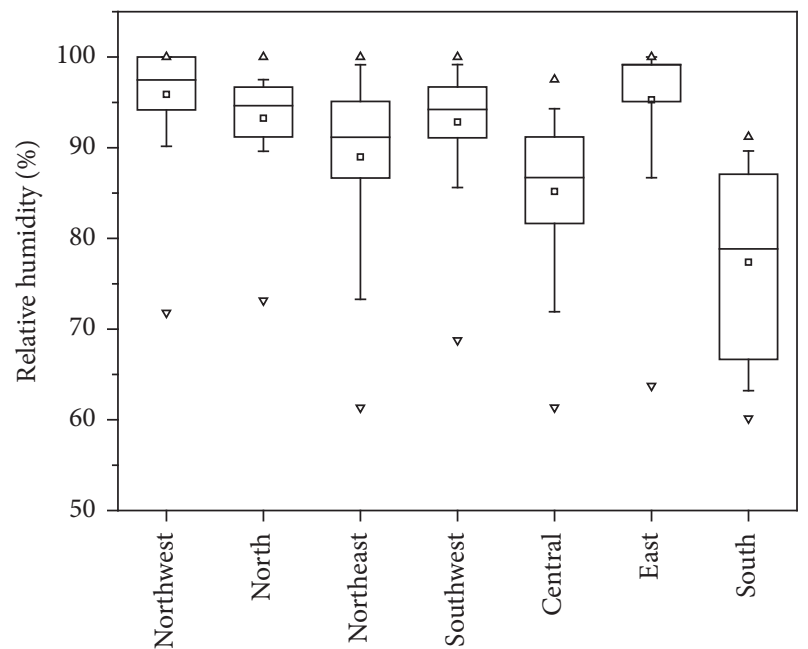

(b)

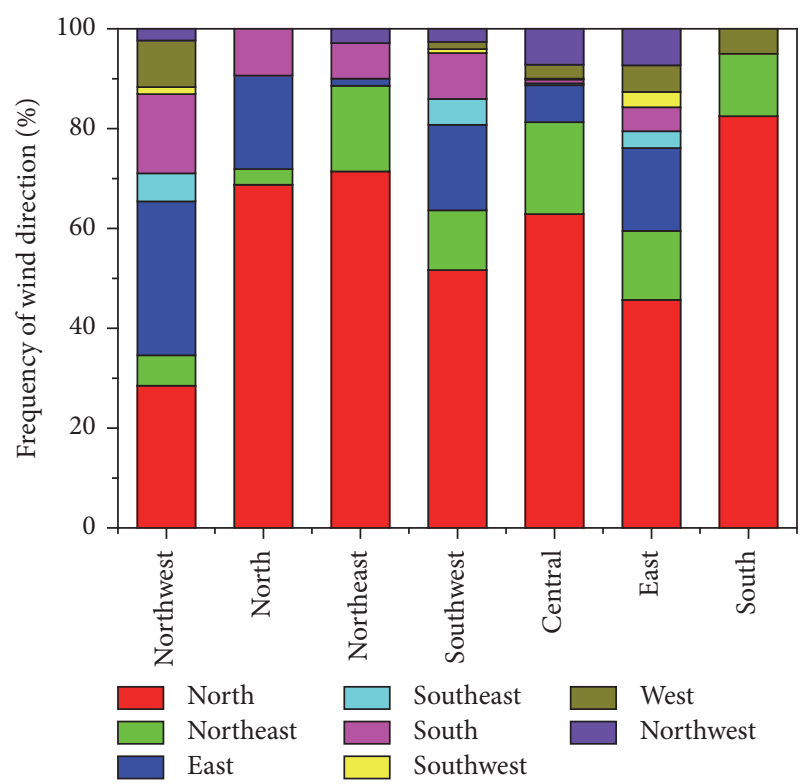

(d)

FIGURE 3: Statistic characteristics of meteorological elements in different regions during the freezing rain events. The wide boxes represent the interquartile range from the 25 th to 75 th percentile. The narrow solid box and the lines represent the mean and median values, respectively. The "whiskers" extend upward to the 90th percentiles and downward to the 10th percentiles. The solid triangles represent the maximum and minimum values, respectively. (a) Temperature; (b) relative humidity; (c) wind speed; (d) frequency of wind direction.

wind speeds are relatively concentrated during freezing rain event. They are mainly in $1 \sim 6 \mathrm{~m} / \mathrm{s}$, averaging at about $3 \mathrm{~m} / \mathrm{s}$ for nearly $80 \%$ of freezing rain events. The variation of wind direction is more regular. In the events of nearly $80 \%$ of freezing rain, the wind direction ranges from north to east. North is the dominant wind direction, and the east is the secondary dominant wind which provides sufficient water vapors for the occurrence of freezing rain, consistent with the characteristics of freezing rain in civil aviation airports of China [32].
3.3. Boundary Layer Characteristics of Freezing Rain. The formation of freezing rain is not only determined by surface meteorological factors, but also more associated with the variations of temperature profiles [33]. Generally, formation conditions of freezing rain formed by supercooled warm rain mechanism are more stricter, in which the raindrops are formed by the collision-coalescence of cloud drops usually occurring in the sky or at the top of mountains, where environment is harsh and few stations are built [34]. Such type of freezing rain only accounts for $6.1 \%$ of total observed 
freezing rains in the statistical analysis of our research. Moreover, as the whole atmosphere is cold layer in the freezing rain formed by supercooled warm rain mechanism, the matching of positive-negative temperature stratifications does not exist. So such type of freezing rain will not be discussed in this section.

Figure 4 shows the distributions of mean atmosphere temperature profiles when freezing rain occurs at four regions of China (Northwest China, North China, and Northeast China are not included due to lack of freezing rain sounding data). By analyzing the temperature profiles of freezing rains in different regions, we can find that although the melting mechanism is the dominant forming mechanism for freezing rains, there are still significant differences in position and thickness of warm layers among different freezing rains. There are mainly two types of freezing rain temperature profiles, including single-warm-layer profile and doublewarm-layer profile. In double-warm-layer profiles, there is a special stratification in which warm layer exists in both near ground and upper air. Hereby we discuss different types of mean temperature profiles when freezing rain happens at different regions and investigate the influence factors (position, thickness, and intensity of cold/warm layer) on the phase state of precipitation particle. In Southwest China, Weining and Guiyang of Guizhou province are selected as typical stations for mountainous area and urban area for comparison, respectively. Weining observes the longest station-hours of freezing rain, which is significantly longer than that of the nearby stations. Guiyang has the secondly most occurrence of freezing rain after Weining but has the most occurrence of freezing rain among provincial capitals of China. The classified study of its profile characteristics would effectively reveal the similarity and difference in the typical stratification distributions between two environments (urban area and mountainous area) in Southwest China.

The temperature profiles of freezing rain at Weining can be divided into 4 types: typical single-warm-layer profile $\mathrm{I}_{\text {Swhill }}$ with warm layer existing at height of $680 \mathrm{hPa}(59 \%)$, single-warm-layer profile $\mathrm{II}_{\mathrm{SWhill}}$ with warm layer existing at height of $560 \mathrm{hPa}(25 \%)$, double-warm-layer profile III $_{\text {SWhill }}$ (11\%) with warm layer existing at both near-ground layer and at height of $560 \mathrm{hPa}(11 \%)$, and double-warm-layer profile $\mathrm{IV}_{\text {SWhill }}$ with warm layer existing at both heights of $600 \mathrm{hPa}$ and $700 \mathrm{hPa}(5 \%)$. In conclusion, the height from $580 \mathrm{hPa}$ to $700 \mathrm{hPa}$ is the position where the warm layer of freezing rain at Weining area is likely to appear. $\mathrm{I}_{\mathrm{SWhill}}$ is the main temperature profile of freezing rain at Weining, and the height and intensity of the warm layer show typical characteristics of freezing rain profile [35-38]. $\mathrm{I}_{\text {SWhill }}$ and $\mathrm{II}_{\text {SWhill }}$ are of identical thickness, which is $65 \mathrm{hPa}$, but have very different intensities. The warm layer of $\mathrm{I}_{\text {Swhill }}$ manifests the lower height and weak intensity, with the highest temperature being only $1.3^{\circ} \mathrm{C}$, which is significantly lower than the highest temperature of $\mathrm{II}_{\text {SWhill }}\left(3.1^{\circ} \mathrm{C}\right)$. Moreover, thickness and intensity of $\mathrm{I}_{\text {SWhill }}$ cold layer are both lower than those of $\mathrm{II}_{\text {Swhill }}$ cold layer significantly, and the lowest temperature of the cold layers is $-2.5^{\circ} \mathrm{C}$ and $-4.9^{\circ} \mathrm{C}$, respectively. This indicates that when the cold layer is thick and strong, the thickness and intensity of warm layer need to increase for precipitation particles to reach supercooled state. $\mathrm{IV}_{\text {SWhill }}$ is similar to $\mathrm{I}_{\text {SWhill }}$ but with a thinner warm layer as compared with $\mathrm{I}_{\text {SWhill, which }}$ indicates that both of the warm layers at $600 \mathrm{hPa}$ and the cold layer between two warm layers contribute to the formation of supercooled precipitation particles, with the increase of the "positive energy" of precipitation particle, promoting the melting process of solid precipitation particle, and making up the insufficient "positive energy" of precipitation particle due to thin thickness of warm layer $[39,40]$. Among the 4 types of profiles, $\mathrm{III}_{\mathrm{SWhill}}$ has the thickest and strongest warm layer. The formation of freezing rain is mainly due to the fully melt of larger solid raindrops, with the supplement of enough "positive energy" under the influence of III $_{\text {SWhill }}[41]$.

For the three types of freezing rain profiles in Guiyang, the near-ground warm layers all locate at height of around $740 \mathrm{hPa}$. $\mathrm{I}_{\text {SWcity }}(84 \%)$ is the main temperature profile for the occurrence of freezing rain in Guiyang, the highest temperature of warm layer is $1.4^{\circ} \mathrm{C}$, and the thickness of warm layer is about $90 \mathrm{hPa}$, which is similar to the typical temperature profile of freezing rain at mountainous area. However, the stratification distributions of urban freezing rain are more regular, and the occurrence proportion of typical freezing rain profiles is $84 \%$, which is significantly higher than the value at mountainous area (59\%). $\mathrm{II}_{\text {SWcity }}$ possesses the similar distribution with $\mathrm{III}_{\mathrm{SWhill}}$ and with the strongest warm layer among the three profile types in Guiyang. III $_{\text {SWcity }}$ has the lowest strength of near-ground warm layer, and the existence of multiple thin warm layers at height of $530 \mathrm{hPa} \sim 650 \mathrm{hPa}$ can provide enough "positive energy" for the melt of solid precipitation particles [42].

In Central and Eastern China, the freezing rain is formatted by the similar single-warm-layer profile $\left(\mathrm{I}_{\mathrm{MC}}\right.$ and $\mathrm{I}_{\mathrm{EC}}$ ), with the warm layers located at height of $760 \mathrm{hPa}$ and $780 \mathrm{hPa}$, the thicknesses are $110 \mathrm{hPa}$ and $130 \mathrm{hPa}$, and the highest temperatures are $2^{\circ} \mathrm{C}$ and $4.5^{\circ} \mathrm{C}$, respectively. Similarly, the thicknesses of cold layer in these two regions are both $210 \mathrm{hPa}$, while the lowest temperatures are $-5.1^{\circ} \mathrm{C}$ and $-6.2^{\circ} \mathrm{C}$, respectively. The warm and cold layers of these two regions are both stronger than those in Southwest China, with no occurrence of multiple warm layers of freezing rain profiles. In Southern China, there is not only the singlewarm-layer profile $\mathrm{I}_{\mathrm{SC}}(69 \%)$, but also the double-warmlayers profile $\mathrm{II}_{\mathrm{SC}}(31 \%)$ including near-ground warm layer. This may be due to the position of stations with freezing rain events. These stations mainly locate at the north boundary of South China, close to the Southwest, Central, and East China, sharing some profile characteristics of freezing rain in these three regions. $\mathrm{I}_{\mathrm{SC}}$ show some characteristics of freezing rain in Central and East China, wherein the warm and cold layers are both thick, while $\mathrm{II}_{\mathrm{SC}}$ shows similar characteristics to the freezing rain's profiles in Southwest China, with the existence of double-warm layer.

3.4. Quantitative-Judgment Method of Freezing Rain. By the comparative analysis of mean temperature profiles of freezing rain at different areas in the above section, we qualitatively illustrated the distributions of warm/cold layers causing the freezing rain and found that there were some relationships among the thickness and intensity of warm/cold layers during 


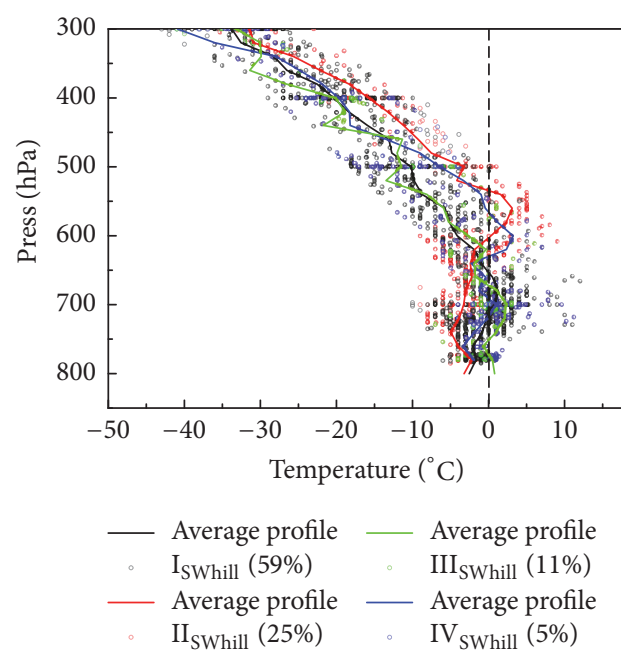

(a)

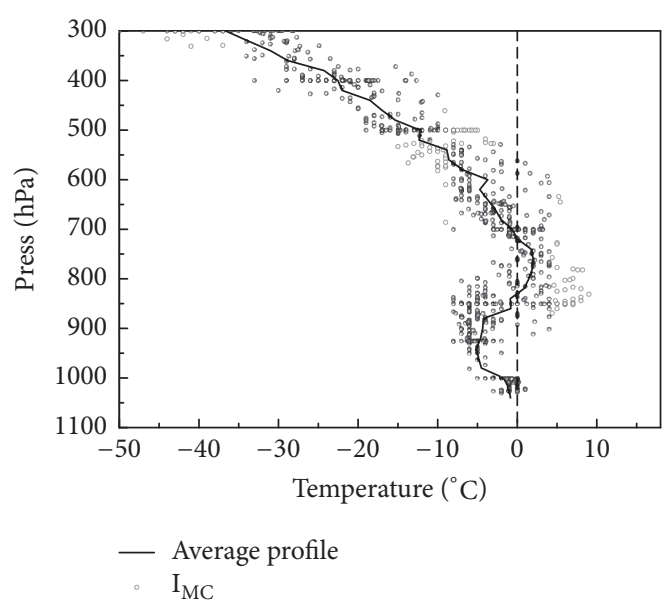

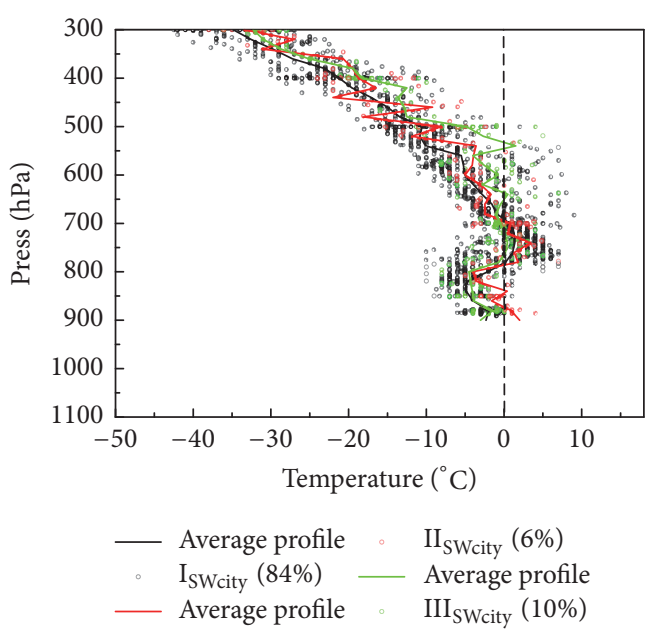

(b)

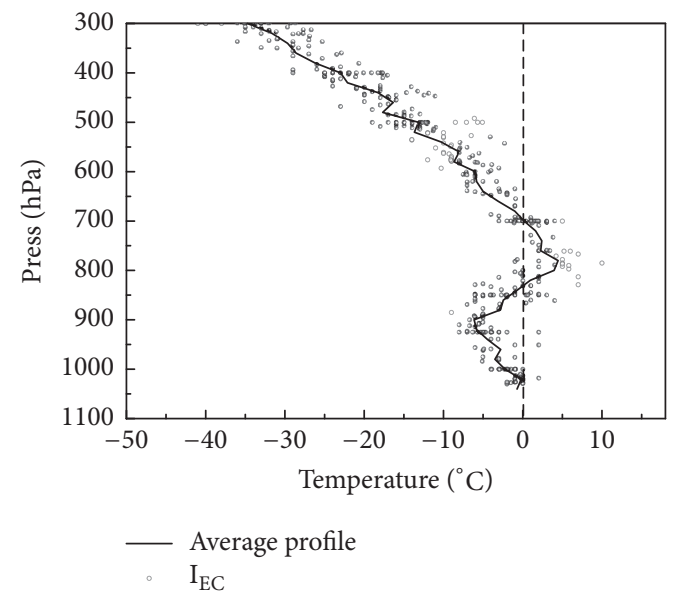

(d)

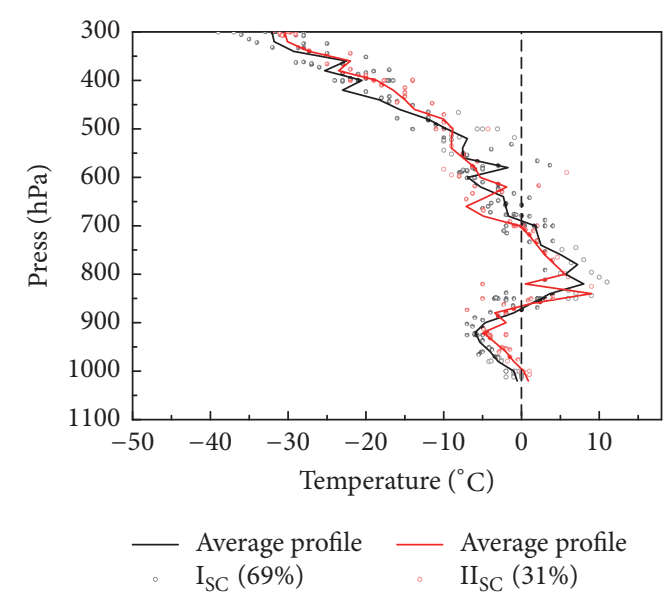

(e)

FIGURE 4: Distributions of mean temperature profiles during freezing rain events in China. (a) Mountainous area of Southwest China; (b) urban area of Southwest China; (c) Central China; (d) East China; (e) South China. 

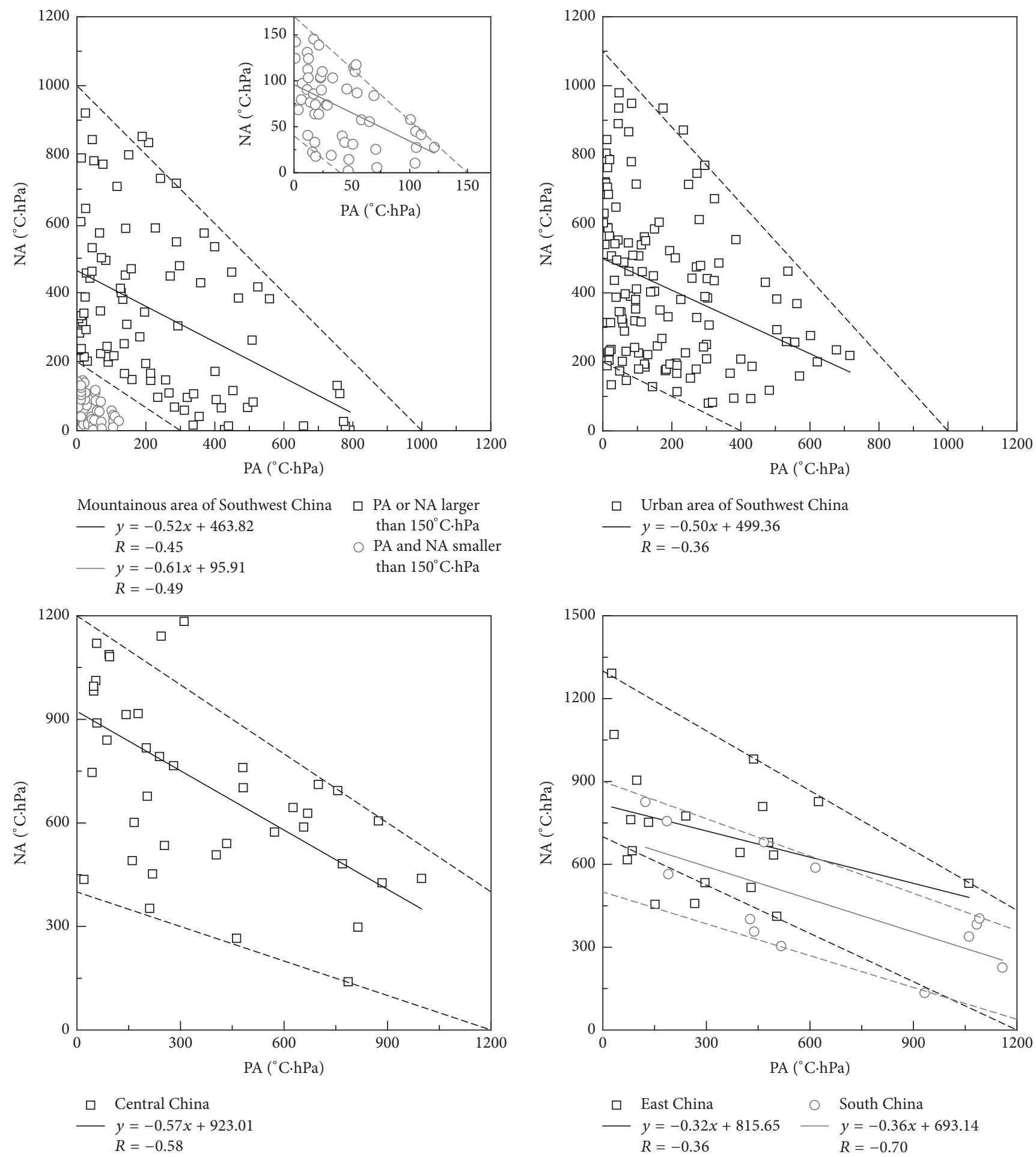

FIGURE 5: Distributions and relationships of PA and NA during freezing rain events in different regions of China from 2000 to 2015.

freezing rain events. Therefore, we conducted the comparative analysis of values of $\mathrm{PA}$ and $\mathrm{NA}$ in different regions and obtained the quantitative relationships between warm and cold layers which were conductive to the occurrence of freezing rain.

Figure 5 presents the distributions and relationships of PA and NA during freezing rain events in different regions of China. For the freezing raining events with multiple warm layers, when the precipitation particle goes through warm layers and the cold layers between warm layers, the heating/cooling process is an accumulative process. Moreover, from the qualitative analysis of the above section, we could see the influence of multiple warm layers on phase state of precipitation particle. Therefore, an accumulative calculation 
method was employed for the PA and NA of freezing rain profile with multiple warm layers. In general, the PA of freezing rain profile is negatively correlated with the NA, with correlation coefficients ranging from -0.36 to -0.70 and the fitting curve slope ranging from -0.26 to -0.61 , and the intercept of curve is $10^{2}$ order. It is worth noting that, with the increase of PA, the NA will decrease during the freezing rain events, which is not consistent with the theoretical perspective: if the PA increases, the NA also needs to increase to guarantee that the relationships between the PA and NA would not be changed for the occurrence of freezing rain. The occurrence of such phenomenon is mainly because the increase of warm-layer areas would compress the areas of cold layer in actual atmosphere, which usually happened in the process when cold front entered the warm air mass deeply $[43,44]$.

Moreover, it can also illustrate that the decreasing rate of $\mathrm{NA}$ is the fastest with the increase of PA in Southwest and Central China affected by freezing rain most severely, with absolute value of slope over 0.5 , while the decreasing rate of NA is relatively slower in the East and South China where the influence of freezing rain disaster is secondly serious, with the absolute values of slope ranging from 0.3 to 0.4 . For Northwest China, North China, and Northeast China which are seldom affected by freezing rain, the decreasing rate of $\mathrm{NA}$ is the smallest. This indicates that the more frequently the regions suffered by freezing rain, the more sensitive the influence between PA and NA is. The more obvious the change of NA with the variations of PA is, the more the freezing rain is likely to occur.

The distributions of PA and NA during freezing rain events in different regions are investigated below. For mountainous area in Southwest China, the distributions of PA and NA can be divided into two types: PA and NA are both smaller than $150^{\circ} \mathrm{C} \cdot \mathrm{hPa}$, and either PA or NA is larger than $150^{\circ} \mathrm{C} \cdot \mathrm{hPa}$. The mountainous area in Southwest China is the only area where freezing rain frequently happens with thin warm/cold layers. Such configuration of warm/cold layers normally occurs under the influence of weak weather system or at the edge of cold front. The relatively loose condition is one of the reasons causing the frequent occurrence of freezing rain in this area. When PA and NA are both smaller than $150^{\circ} \mathrm{C} \cdot \mathrm{hPa}$, the configuration of warm and cold layer meets the formula of $-\mathrm{PA}+40 \leq \mathrm{NA} \leq-1.13 \mathrm{PA}+170$, and they are both larger than $20^{\circ} \mathrm{C} \cdot \mathrm{hPa}$, freezing rain will happen. However, when either PA or NA is larger than $150^{\circ} \mathrm{C} \cdot \mathrm{hPa}$, the configuration of warm and cold layer meets the formula of $-0.67 \mathrm{PA}+200 \leq \mathrm{NA} \leq-\mathrm{PA}+1000$, and they are both smaller than $1000^{\circ} \mathrm{C} \cdot \mathrm{hPa}$, freezing rain will happen. The range of PA and NA in this area is the largest than the other regions when freezing rain is happening. This further indicates that such configuration of weak cold and warm layer is one of major reasons causing frequent freezing rain at mountainous areas of Southwest China. Moreover, the distribution of PA and NA at urban area is similar to that at mountainous area in Southwest China. The values of PA and NA would not be smaller owing to the heat-island influence of city during freezing rain events [45]. When either PA or NA is larger than $150^{\circ} \mathrm{C} \cdot \mathrm{hPa}$, the configuration of warm/cold layer meets the formula of $-0.50 \mathrm{PA}+200 \leq \mathrm{NA} \leq-1.1 \mathrm{PA}+1100$, and the PA and NA locate at the range of $0 \sim 600^{\circ} \mathrm{C} \cdot \mathrm{hPa}$ and $100 \sim 1000^{\circ} \mathrm{C} \cdot \mathrm{hPa}$, respectively. When freezing rain happens in Central and East China, PA locates at the range of 0 $900^{\circ} \mathrm{C} \cdot \mathrm{hPa}$ and $0 \sim 600^{\circ} \mathrm{C} \cdot \mathrm{hPa}$ and NA locates at the range of $300 \sim 1200^{\circ} \mathrm{C} \cdot \mathrm{hPa}$ and $450 \sim 1000^{\circ} \mathrm{C} \cdot \mathrm{hPa}$, with the formula of $-0.33 \mathrm{PA}+400 \leq \mathrm{NA} \leq-0.67 \mathrm{PA}+1200$ and $-0.58 \mathrm{PA}+$ $700 \leq \mathrm{NA} \leq-0.72 \mathrm{PA}+1300$, respectively. In South China, $\mathrm{PA}$ and NA of freezing rain meet the formula of $-0.38 \mathrm{PA}+$ $500 \leq \mathrm{NA} \leq-0.45 \mathrm{PA}+900$, mainly concentrated in the range of $100 \sim 1200^{\circ} \mathrm{C} \cdot \mathrm{hPa}$ and $300 \sim 8000^{\circ} \mathrm{C} \cdot \mathrm{hPa}$, which are significantly smaller than those of other regions, indicating that the conditions of stratification configuration to the occurrence of freezing rain in South China are relatively stricter. The freezing rain is a rare event in Northwest, North, and Northeast China; therefore, the analysis of distributions of PA and NA is not conducted.

\section{Conclusions}

(1) The freezing rain will happen in the total 7 regions in China. Among them, Southwest, Central, and Eastern China suffer more freezing rain. The freezing rain of China is generally in stripe-shape spatial distribution, wherein the area $\left(106^{\circ} \mathrm{E}, 26^{\circ} \mathrm{N}\right)$ has the most frequent freezing rain. The station-number of freezing rain that has been observed accounts for $26.9 \%$ of total stations, with $0 \sim 10$ station-hours accounting for $64.6 \%$ of the stations, where freezing rain could be observed. The stations with freezing rain over 100 station-hours are mainly concentrated at southeast areas of Southwest China and high-elevation mountainous areas of Eastern China. Weining of Guizhou province has the most frequent occurrence of freezing rain, with 1848 station-hours.

(2) The variation of freezing rain's station-hour is featured by small fluctuation with sudden rise, and the variation of freezing rain during 2008-2015 is significantly stronger than that during 2000-2007. The daily variation of freezing rain's station-hour follows the law of "more in nighttime while less in daytime." The frequency of freezing rain at 14:00 is the lowest, while it reaches the highest value at $08: 00$. The stationhour of freezing rain during 20:00 08:00 is 2.7 times of that during 11:00 17:00. The temperature ranges from -3 to $1^{\circ} \mathrm{C}$, the relative humidity ranges from $85 \%$ to $100 \%$, the wind speed ranges from 1 to $6 \mathrm{~m} \mathrm{~s}^{-1}$, and the wind direction ranges from north to east; these are the favorable conditions to the occurrence of freezing rain.

(3) The temperature profile of freezing rain could be divided into two types, including single-warm-layer profile and double-warm-layer profile, with existence of two warm layers both in the upper air or one in the upper air and the other near the surface. The height of single warm layer at southwest mountainous area is the highest, which is around $560 \mathrm{hPa}$, while the height of single warm layer at other regions is generally at $750 \mathrm{hPa}$. The warm layers and cold layer between them both contribute to the formation of supercooled raindrops. The freezing rain profiles of southwest mountainous area and urban area are similar to each other; however, the distribution law of freezing rain profiles at 
urban area is more regular, with $84 \%$ of freezing rain events meeting the characteristics of type single-warm-layer profile. The freezing rain shares similar temperature profile in Central and East China, which are both manifested as typical single-warm-layer profile, and the temperature profile in South China is similar to that in both Southwest China and Central/East China, which is manifested as typical singlewarm-layer profile and double-warm-layer profile.

(4) PA is negatively correlated with NA, with correlation coefficient ranging from -0.36 to -0.70 , the variation range of fitting curve slope is from -0.26 to -0.61 , and the intercept of curve is $10^{2}$ order. The more seriously the regions suffer by freezing rain, the more sensitive the influence between PA and NA is. The more obvious the adjustment of NA to the variations of PA is, the more the freezing rain is likely to occur. The mountainous area in Southwest China is the only area where freezing rain happens with thin warm/cold layers (PA and NA are both lower than $150^{\circ} \mathrm{C} \cdot \mathrm{hPa}$ ). The loose condition may be the main reason causing the frequent occurrence of freezing rain at this area, while stratification configuration to the occurrence of freezing rain in South China is stricter.

\section{Conflicts of Interest}

The authors declare that they have no conflicts of interest.

\section{Acknowledgments}

This work is supported by the National Natural Science Foundation of China (Grant No. 41505121, 41375138, 41675136, and 41375137), and the Natural Science Foundation of Hubei Province (2016CFB347).

\section{References}

[1] Y. Hu, "Analysis and countermeasures for large area accident cause by icing on transmission line," Gaodianya Jishu/High Voltage Engineering, vol. 31, no. 4, pp. 14-15, 2005.

[2] O. Parent and A. Ilinca, "Anti-icing and de-icing techniques for wind turbines: Critical review," Cold Regions Science and Technology, vol. 65, no. 1, pp. 88-96, 2011.

[3] N. Davis, A. N. Hahmann, N.-E. Clausen, and M. Žagar, "Forecast of icing events at a wind farm in Sweden," Journal of Applied Meteorology and Climatology, vol. 53, no. 2, pp. 262-281, 2014.

[4] P. Y. Chen, B. Cao, X. Luo, and R. Z. Chen, "Operation data and feature analysis of the main natural disasters of power network in China," Electric Power, vol. 47, no. 7, pp. 57-61, 2014.

[5] Z. Wang, "Climatic characters and changes of ice freezing days in China," Chinese Journal of Atmospheric Sciences, vol. 35, no. 3, pp. 411-421, 2011.

[6] J. C. Zhang, Pandect of Climate in China, Meteorological Press, Beijing, China, 1991.

[7] Z. Wang, "Characters of changes in extensive and persistent ice freezing processes of China in recent 50 years," Plateau Meteor, vol. 33, no. 1, pp. 179-189, 2014 (Chinese).

[8] S. S. Zhao, G. Gao, Q. Zhang, Z. Y. Wang, and S. Q. Yin, "Climate characteristics of freezing weather in China," Meteorological Monthly, vol. 36, no. 3, pp. 34-38, 2010 (Chinese).
[9] R. M. Rauber, L. S. Olthoff, M. K. Ramamurthy, and K. E. Kunkel, "The relative importance of warm rain and melting processes in freezing precipitation events," Journal of Applied Meteorology, vol. 39, no. 7, pp. 1185-1195, 2000.

[10] B. E. Martner, J. B. Snider, R. J. Zamora, G. P. Byrd, T. A. Niziol, and P. I. Joe, "A remote-sensing view of a freezing-rain storm," Monthly Weather Review, vol. 121, no. 9, pp. 2562-2577, 1993.

[11] R. Ashenden and J. D. Marwitz, "Turboprop aircraft performance response to various environmental conditions," Journal of Aircraft, vol. 34, no. 3, pp. 278-287, 1997.

[12] R. Ashenden and J. Marwitz, "Characterizing the supercooled large droplet environment with corresponding turboprop aircraft response," Journal of Aircraft, vol. 35, no. 6, pp. 912-920, 1998.

[13] G. J. Huffman and G. A. Norman Jr., "The supercooled warm rain process and the specification of freezing precipitation," Monthly Weather Review, vol. 116, no. 11, pp. 2172-2182, 1988.

[14] J. R. Bocchieri, "The objective use of upper air soundings to specify precipitation type.," Monthly Weather Review, vol. 108, no. 5, pp. 596-603, 1980.

[15] R. M. Rauber, M. K. Ramamurthy, and A. Tokay, "Synoptic and mesoscale structure of a severe freezing rain event: the St. Valentine's day ice storm," Weather \& Forecasting, vol. 9, no. 2, pp. 183-208, 1994.

[16] J. M. Thériault, R. E. Stewart, and W. Henson, "On the dependence of winter precipitation types on temperature, precipitation rate, and associated features," Journal of Applied Meteorology and Climatology, vol. 49, no. 7, pp. 1429-1442, 2010.

[17] A. T. DeGaetano, B. N. Belcher, and P. L. Spier, "Short-term ice accretion forecasts for electric utilities using the weather research and forecasting model and a modified precipitationtype algorithm," Weather and Forecasting, vol. 23, no. 5, pp. 838853, 2008.

[18] R. Derouin, "Experimental forecast of freezing level(s, conditional precipitation type, surface temperature, and 50-meter wind, produced by the planetary boundary layer (PBL) model," NOAA Tech. Procedures Bull, vol. 101, p. 8, 1973.

[19] A. Cantin and D. Bachand, "Synoptic pattern recognition and partial thickness technique as a tool for precipitation types forecasting associated with a winter storm," Tech. Note 93n-002, Centre Meteorologique du Quebec, 1993.

[20] J. Ramer, "An empirical technique for diagnosing precipitation type from model output. Preprints," in Proceedings of the Fifth Int. Conf. on Aviation Weather Systems, pp. 227-230, Vienna, VA, USA, 1993.

[21] T. G. Houston and S. A. Changnon, "Freezing rain events: a major weather hazard in the conterminous US," Natural Hazards, vol. 40, no. 2, pp. 485-494, 2007.

[22] P. Bourgouin, "A method to determine precipitation types," Weather and Forecasting, vol. 15, no. 5, pp. 583-592, 2000.

[23] Y. F. Zhang, "Variation trend of climatic calamities in the past 50 years in Guizhou," Journal of Chengdu Institute of Meteorology, vol. 14, no. 1, pp. 88-92, 1999.

[24] Y. M. Zhang, X. Gu, H. T. Chen, J. Zhong, P. Liu, and B. Chen, "Temporal and spatial characteristics of freezing rain days over the northwestern Guizhou Plateau," Resources Science, vol. 33, no. 3, Article ID 477482, 2011.

[25] Y. Tang, W. Z. Zhou, and G. P. Xi, "Analysis on mechanism of freezing rain climate and weather in Guangxi," Journal of Catastrophology, vol. 26, no. 2, pp. 24-30, 2011. 
[26] F. C. You, G. Q. Fu, Z. Liu, and Y. Gu, "Analysis of spatiotemporal distribution and sounding temperature-humidity characteristics of freezing rain in Beijing area," Meteorological Monthly, vol. 41, no. 12, pp. 1488-1493, 2015.

[27] X. D. Yan, Z. P. Wu, and S. H. Gu, "Analyses on the spacetime distribution characteristics and their influence factors of freezing rain in Guizhou province," Plateau Meteorology, vol. 28, no. 3, pp. 694-701, 2009 (Chinese).

[28] China Meteorological Administration, Surface meteorological code handbook, Meteorological Press, Beijing, China, 1999.

[29] J. Cortinas Jr., "A climatology of freezing rain in the Great Lakes Region of North America," Monthly Weather Review, vol. 128, no. 10, pp. 3574-3588, 2000.

[30] Y. Zhou, S. Niu, J. Lü, and Y. Zhou, “The effect of freezing drizzle, sleet and snow on microphysical characteristics of supercooled fog during the icing process in a mountainous area," Atmosphere, vol. 7, no. 11, article no. 143, 2016.

[31] Y. Zhou, S. Niu, and J. Lü, “The influence of freezing drizzle on wire icing during freezing fog events," Advances in Atmospheric Sciences, vol. 30, no. 4, pp. 1053-1069, 2013.

[32] J. Li, X. L. Guo, X. N. Zhou, and X. Y. Li, "Characteristics of freezing rain, freezing drizzle, and freezing fog in China from 2011 to 2013," Chinese Journal of Atmospheric Sciences, vol. 39, no. 5, pp. 1038-1048, 2015.

[33] W. H. Qian and J. L. Fu, "Frontal genesis of moisture atmosphere during the early 2008 persistent freezing-rain event in southern China," Science China Earth Sciences, vol. 53, no. 3, pp. 454-464, 2010.

[34] Z. Zhang, Y. X. Han, J. Wang, and C. R. Liu, "Microphysics characteristics and causes of freezing precipitation in mountainous area over Yunnan-Guizhou Plateau," Journal of the Meteorological Sciences, vol. 36, no. 3, pp. 389-395, 2016.

[35] X. E. Liu, Q. Gao, H. He, J. Li, X. Y. Li, and X. C. Jia, "A numerical simulation on cloud physical characteristics of freezing rain," Climatic and Environmental Research, vol. 22, no. 2, pp. 191-202, 2017.

[36] Y. Tao, H. Y. Li, and W. G. Liu, "Characteristics of atmospheric stratification and cloud physics of different types of freezing rain over southern China," Plateau Meteor, vol. 32, no. 2, pp. 501-518, 2013.

[37] Z. P. Zong, J. Ma, H. D. Zhang, and C. Hua, "Analysis on the spatial-temporal characteristics of freezing rain in recent decades," Meteorological Monthly, vol. 39, no. 7, pp. 813-820, 2013.

[38] X. L. Wang, X. Y. Li, Z. X. Li, N. Z. Li, and J. L. Ju, "Analysis of freezing-hazard event in, 2005, in Hunan province," Meteorological Monthly, vol. 32, no. 2, pp. 87-91, 2006 (Chinese).

[39] H. Xu and R. H. Jin, "Analysis of influence of terrain on freezingrain weather in Hunan in the early 2008," Plateau Meteorology, vol. 29, no. 4, pp. 957-967, 2010.

[40] J. H. Sun and S. X. Zhao, "Quasi-stationary front and stratification structure of the freezing rain and snow storm over southern China in," Climatic and Environmental Research, vol. 13, no. 4, pp. 368-384, 2008.

[41] C. R. Liu, Y. X. Han, J. Wang, and Z. Zhang, "Studies on statistics and formation mechanism of freezing rain," Journal of Catastrophology, vol. 30, no. 3, pp. 219-222, 2015.

[42] M. J.Zeng, W. S. Lu, X. Z. Liang, H. Y. Wu, M. J. Pu, and D. P. Yin, "Analysis of temperature structure for persistent disasterous freezing rain and snow over southern China in early 2008," Acta Meteorologica Sinica, vol. 66, no. 6, pp. 1043-1052, 2008.
[43] R. E. Stewart, "Precipitation types in winter storms," Pure and Applied Geophysics PAGEOPH, vol. 123, no. 4, pp. 597-609, 1985.

[44] D. A. Gay and R. E. Davis, "Freezing rain and sleet climatology of the southeastern USA," Climate Research, vol. 3, no. 3, pp. 209-220, 1993.

[45] S. A. Changnon, "Notes and correspondence urban modification of freezing-rain events," Journal of Applied Meteorology, vol. 42, no. 6, pp. 863-870, 2003. 

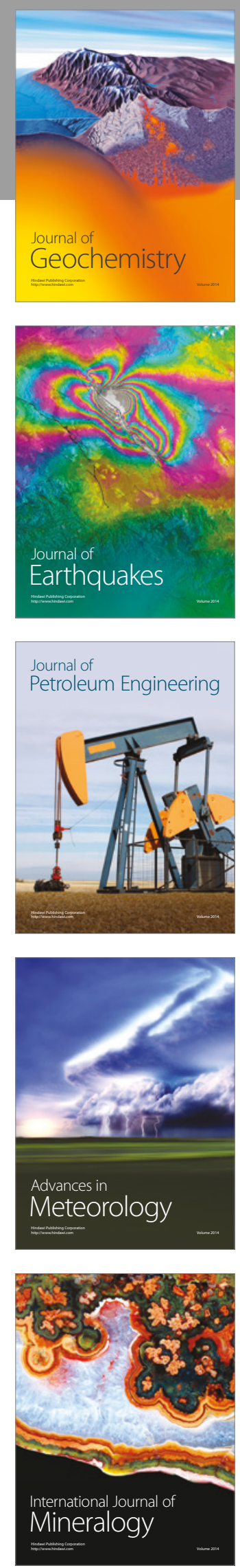
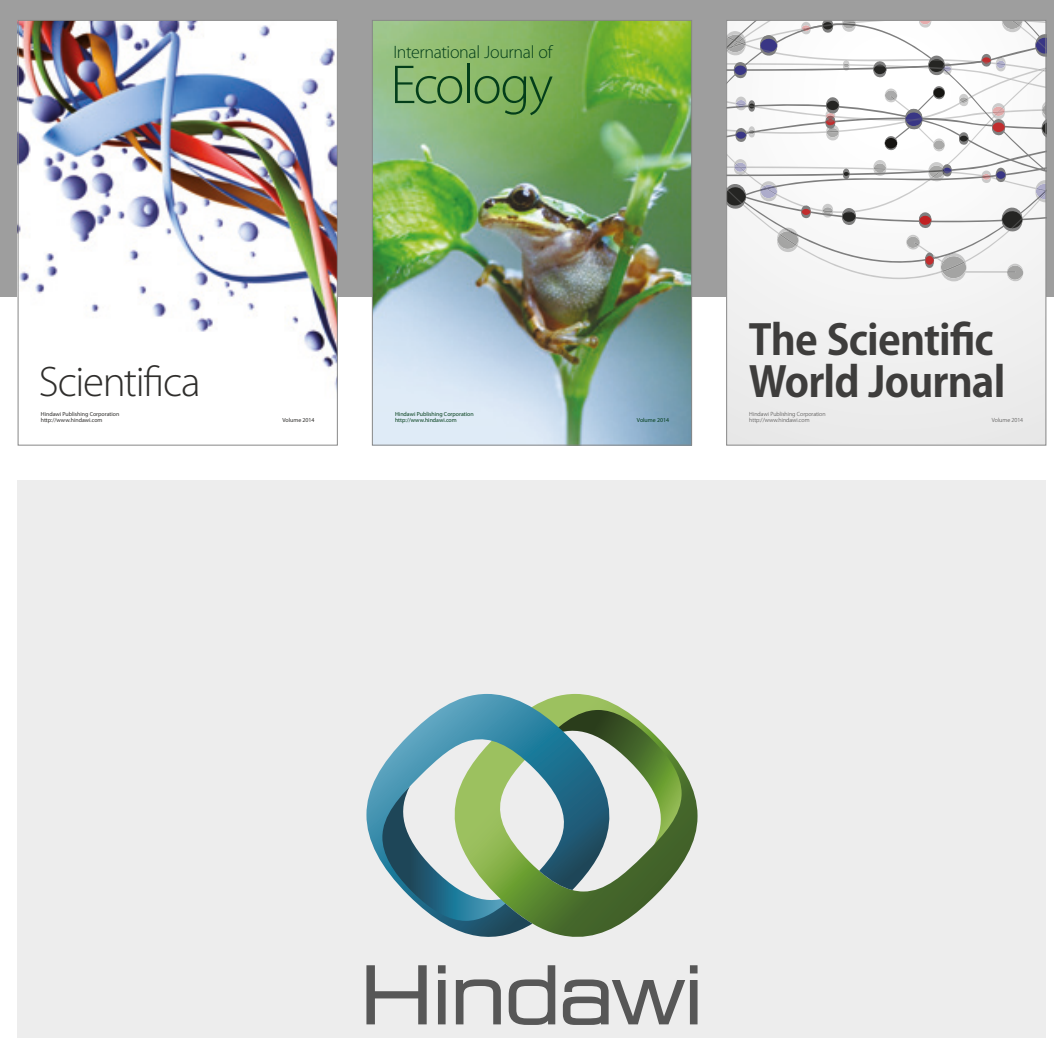

Submit your manuscripts at

https://www.hindawi.com
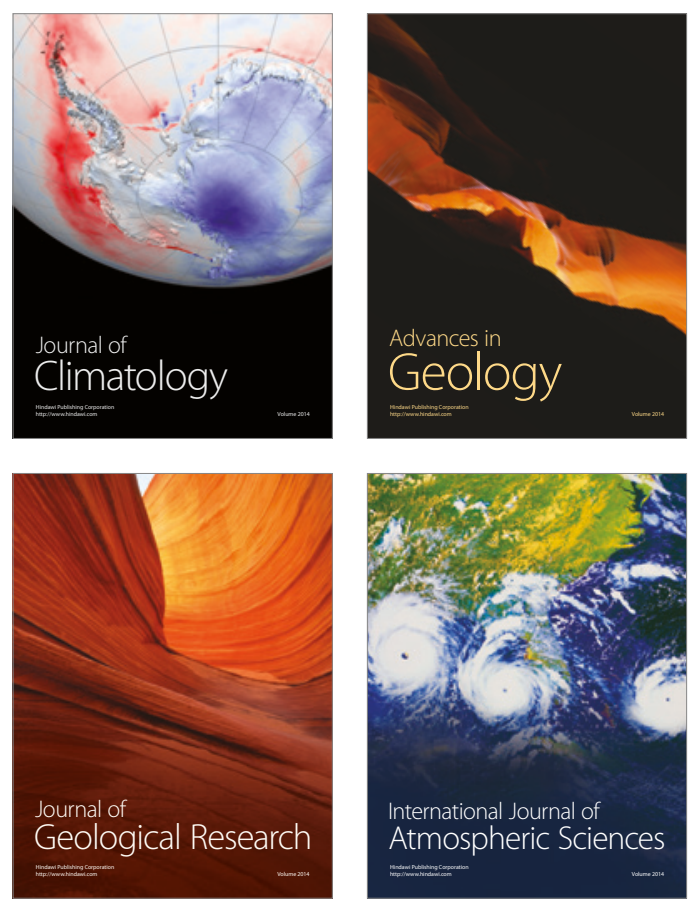

The Scientific

World Journal
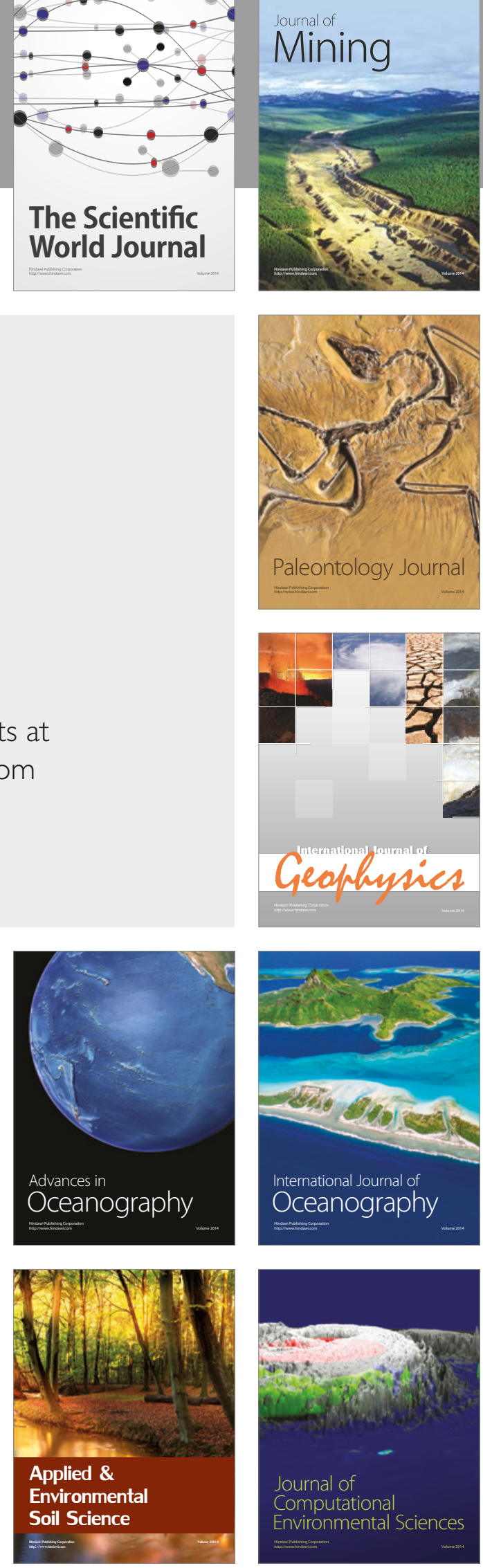